\title{
Mersin Photogrammetry Journal
}

https://dergipark.org.tr/en/pub/mephoj

e-ISSN 2687-654X

\section{Using photogrammetric modeling in reverse engineering applications: Damaged turbocharger example}

\author{
Engin Kanun*1] \\ ${ }_{1}^{1}$ Mersin University, Faculty of Engineering, Mechanical Engineering Department, Mersin, Turkey
}

\section{Keywords}

Mechanical Parts Modeling

Photogrammetry

Reverse Engineering

Turbocharger

3D Modeling

\begin{abstract}
Engineering in different areas such as design, manufacture, quality control, research and development, damage analysis, etc. increasingly needs fast, detailed and accurate threedimensional (3D) documentation of mechanical parts. Moreover, not only in the production and design processes, but also in the post-production stages, the details of the parts may need to be documented in the exact dimensions. Identifying an assembly's components and their interrelationships, producing new digital 2D-3D models of the assembly or parts, rebuilding a part or assembly, examining parts to ensure quality and tolerances, improving performance and if there are any, determining the damaged sections are some of the essential applications of reverse engineering. The purpose of this article is to demonstrate the implementation of a low cost scanning system to create digital copies of mechanical parts. In this study, a mobile phone-based photogrammetric technique is applied to obtain a 3D model of the damaged turbocharger of a car. Firstly, the turbocharger was dismantled into two parts. Both parts were individually modeled and then assembled together. Thus, the turbo wings under the covers were modeled in detail. Accuracy analysis in terms of dimensions was performed in the obtained model. Finally, a simple CFD application was made on a section of the compressor wheel of the turbocharger. Accuracy analyzes of the 3D models showed that less than $0.5 \mathrm{~mm}$ accuracy can be obtained without difficulty.
\end{abstract}

\section{INTRODUCTION}

In the fields of mechanical engineering and industrial production, reverse engineering (RE) is considered as a method of producing engineering design data and documentation from existing parts and their assemblies (Kumar et al. 2013). The main objective of the RE process, considering engineering applications, is to obtain information from the acquired raw data to recreate a proper parametric CAD model that is as accurate as possible to the object's original design. The composing CAD features are expected to be precise in their dimensions, combinatorial structure and in their current relations (i.e. geometric constraints, symmetries, regularities) between them. Due to the growth and dissemination of 3D scanning technologies and the increasing number of potential applications, the reconstruction of digital geometric models of physical objects, typically referred to as Reverse Engineering (RE) in the field of Computer Aided Design (CAD), has been extensively studied in recent years (Buonamici et al. 2018).

There are plenty of reasons to use RE. The main purpose of selecting RE as a method of development is the absence of a 3D CAD digital model (Dúbravcík and Kender 2012). For parts that have to be duplicated or modified, CAD models are often unavailable or unusable. This is a substantial problem for long life cycle systems for which replacement part inventories have been exhausted and original suppliers are unable or unwilling to provide custom production runs of replacement parts at affordable prices and in a timely manner. Either the CAD systems were not included in the original design or the original design documentation is otherwise insufficient or unreliable for many parts. CAD models, even when they exist, may not be adequate to permit modification or manufacturing using conventional technologies for a number of reasons. Production line alterations to the original design may indicate that the geometry of the component is no longer accurately

* Corresponding Author

*(ekanun@mersin.edu.tr) ORCID ID 0000- 0002 - 2369 - 5322
Cite this study

Kanun E (2021). Using photogrammetric modeling in reverse engineering applications: Damaged turbocharger example. Mersin Photogrammetry Journal, 3(1), 21-28 
represented by the original CAD model. To generate CAD models of a part based on sensed data acquired using three-dimensional (3-D) position digitization techniques, reverse engineering methodologies can be used (Thompson et al. 1999).

Since it usually refers to a product with geometrically complex freeform shapes, measuring and modeling such a component with traditional measurement methods is very difficult (Yılmaz et al. 2008). The use of scanned data in the form of point clouds enables the designer of a machine to produce a detailed CAD 3D model, which can then be used for determining manufacturing quality, CAE system-based redesigning, engineering and simulation tests, and many more (Deja et al. 2019).

Reverse engineering is utilized in engineering, medical sciences, restoration processes for the conservation of cultural heritage, automotive industry, shipbuilding industry etc. (Yllmaz et al. 2000; Verim and Yumurtacı 2020; Dúbravcík and Kender 2012; Deja et al. 2019).

When mechanical engineering applications are taken into consideration, the essential aim of the reverse engineering is to generate a 3D parametric solid model, which is the most appropriate to the original of the object, by utilizing raw data received from a 3D scanner (Verim and Yumurtaci 2020). Shape engineering, placed at the interface of mechanical engineering, modern geometry, computer science, and statistics, is concerned with the study of mechanical parts and assemblies' geometric properties (Anwer and Mathieu 2016). As an example, the proper functioning of mechanical parts frequently depends on the geometric interrelations between functional surfaces or properties (e.g. parallelism between two planes, orthogonality between axes, etc.) and their repair is essential in most cases (Buonamici et al. 2018).

In the documentation process, photogrammetry is a stand-alone tool (Unal et al. 2004; Ulvi et al. 2019). This method relies on at least two images with overlapping data to ensure that the triangulation process is effective (Yakar and Yılmaz, 2008). The aim of digital close-range photogrammetry is to simplify and accelerate the data recording and processing (Doğan and Yakar 2018).

In this study, mobile phone-based photogrammetry which is a fast, cost-efficient and easy to use method was utilized for 3D model construction.

In the first part of the study, the photographs of the model were taken during the photogrammetric model creation process. Point cloud was obtained in ContextCapture software from the photos taken later. The obtained point cloud was transferred to Agisoft Metashape software and data filtering process was applied. Finally, the 3D solid model was created and accuracy analysis of the obtained 3D model was completed.

The second step of the study includes surface and damage analysis of the turbocharger. The obtained 3D model of the turbocharger had been investigated in terms of stresses and strains by using Ansys Static Structural module.

This paper provides a RE approach to obtain the initial design specifications of mechanical parts and affirms an inspection procedure for them to ensure their consistent performance in the second lifecycle by utilizing mobile phone-based photogrammetric techniques. It also provides an approach to assist the progress of remanufacturing, rebuilding, repairing, modificating, improving etc..

\section{METHOD}

In this paper, mobile phone-based photogrammetric survey was implemented to obtain the 3D model of the turbocharger which is examined in this study. The damaged turbocharger was dismantled from a 2004 Ford Fusion TDCi car.

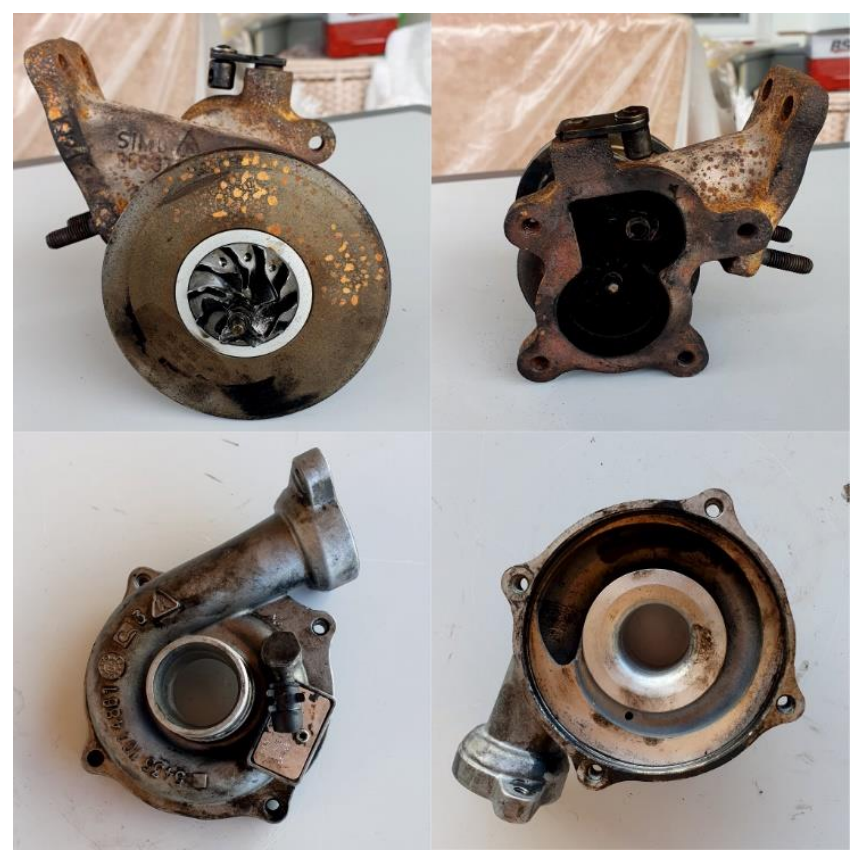

Figure 1. Damaged turbocharger of 2004 Ford Fusion TDCi - separated into components

This study consists of two phases such as field work and office work. During the field work, photogrammetric images were captured with the aim of obtaining the 3D model of the turbocharger. Digital images of the turbocharger were acquired by using Samsung Galaxy S10 mobile phone. The mobile phone has three rear cameras. The main camera of the phone has 12megapixels with a 5.6x4.2 mm sensor size. Auto-focusing and focusing at infinity settings were applied. The minimum focusing distance of the camera is $0.10 \mathrm{~m}$ and the hyperfocal distance of the camera is $3.60 \mathrm{~m}$. The lens of the camera has a focal length of $4.32 \mathrm{~mm}$ and (f/1.5) aperture. Focal length (35 mm eq.) is $27.7714 \mathrm{~mm}$. In addition, the lens has a $66.3^{\circ}$ horizontal field of view and $52.2^{\circ}$ vertical field of view. Magnification factor was $1 \mathrm{x}$ for all photos taken. In addition to all these, camera calibration was performed and the calibration coefficients of the camera were calculated.

First step of the field work was separating the turbocharger into its components for the purpose of creating the detailed 3D model of the components such as turbo-housing, turbo wings of inlet and outlet sides, the main cover etc. After the separation step, camera calibration was completed. A constant focal length during the acquisition and a constant and homogeneous lighting were utilized as much as possible. Blurry photos, flash 
light, optical stabilization, digital zoom, and fish-eye lenses were avoided in order to produce better results. With these adjustments, a total of 600 images of the turbocharger were taken.

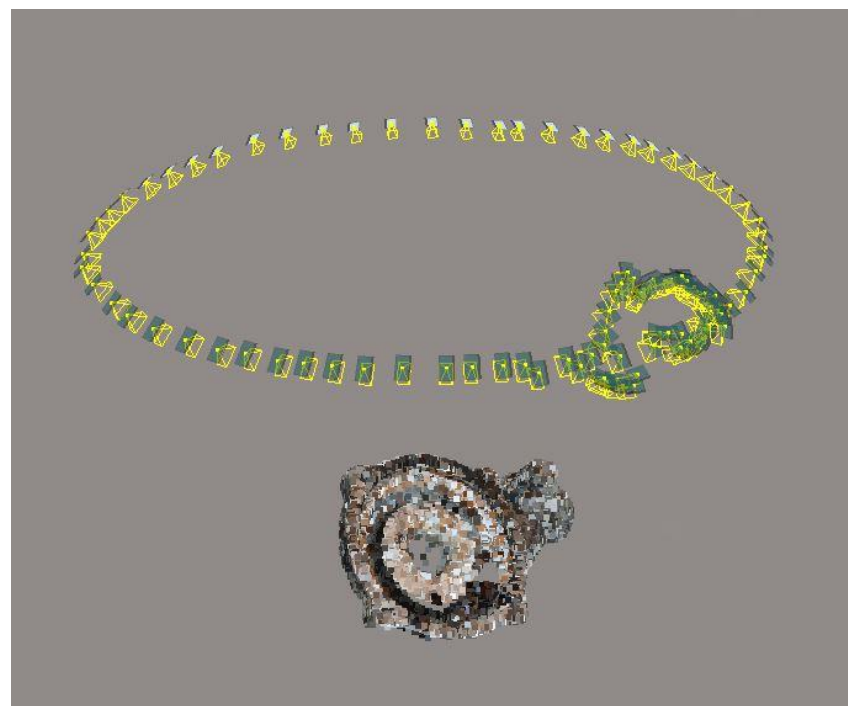

Figure 2. Camera stations configuration of turbohousing (inside)

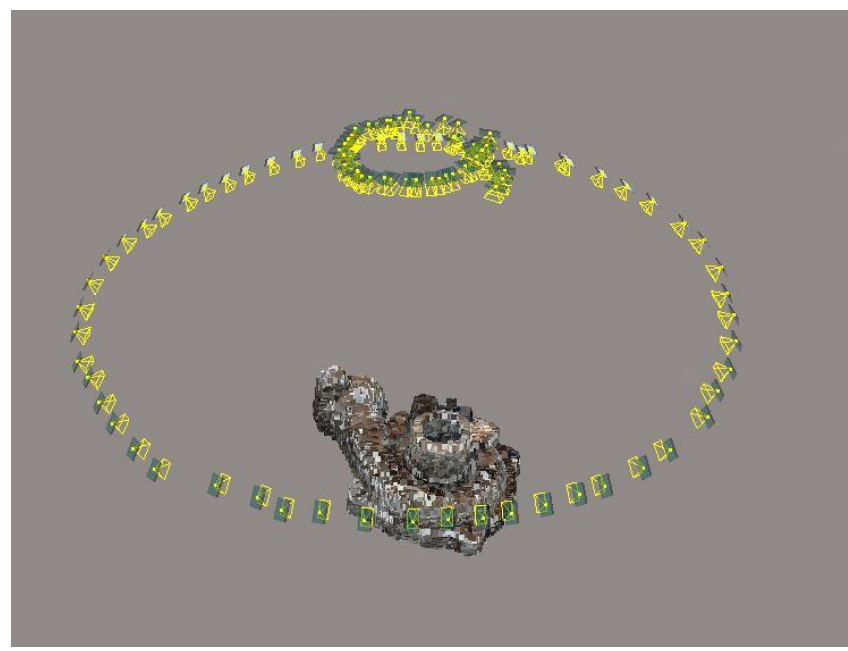

Figure 3. Camera stations configuration of turbohousing (outside)

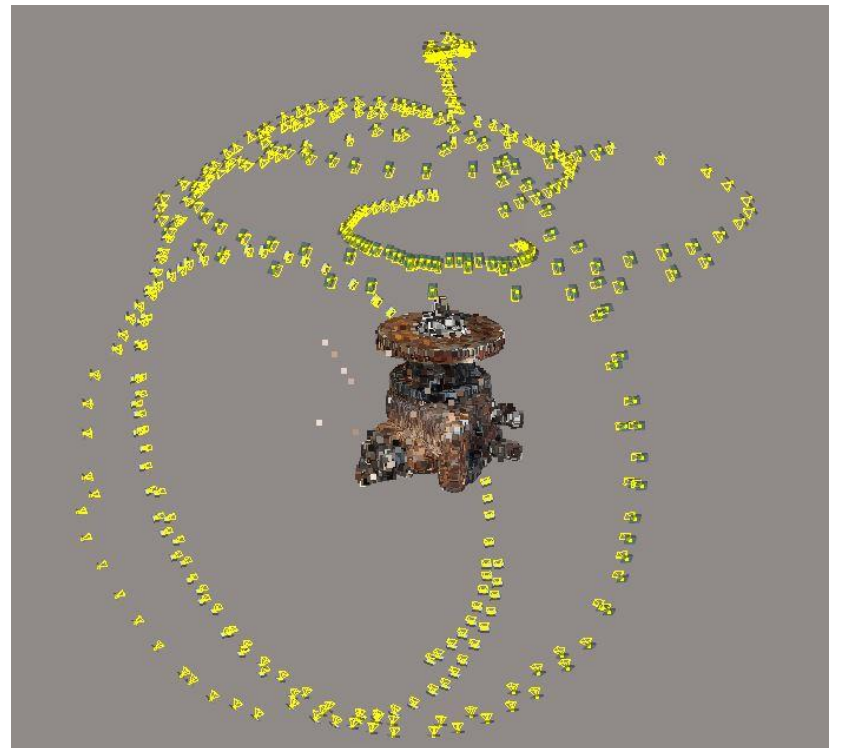

Figure 4. Camera stations configuration of main component and inlet-outlet sides

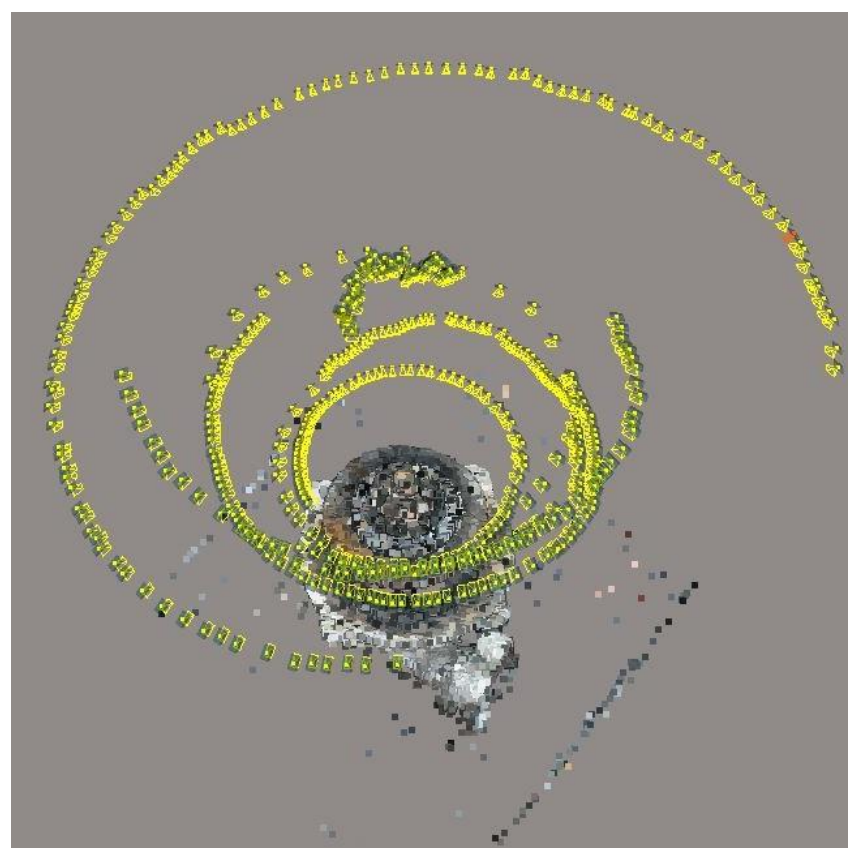

Figure 5. Camera stations configuration of turbine (exhaust-side)

After the completion of the field work, the office work phase was initiated. During the office phase of the study, 599 of the images were processed at Bentley's ContextCapture Software.

Two user tie points were marked on every component of the turbocharger to submit an accurate triangulation to the photos. Then, by taking precise measurements on the parts of the turbocharger, predefined positioning and scale constrains were generated with two user tie points that marked before. Generic block type option was selected with the aim of helping the triangulation process. 'Keep camera calibration' option was selected for aerotriangulation process.

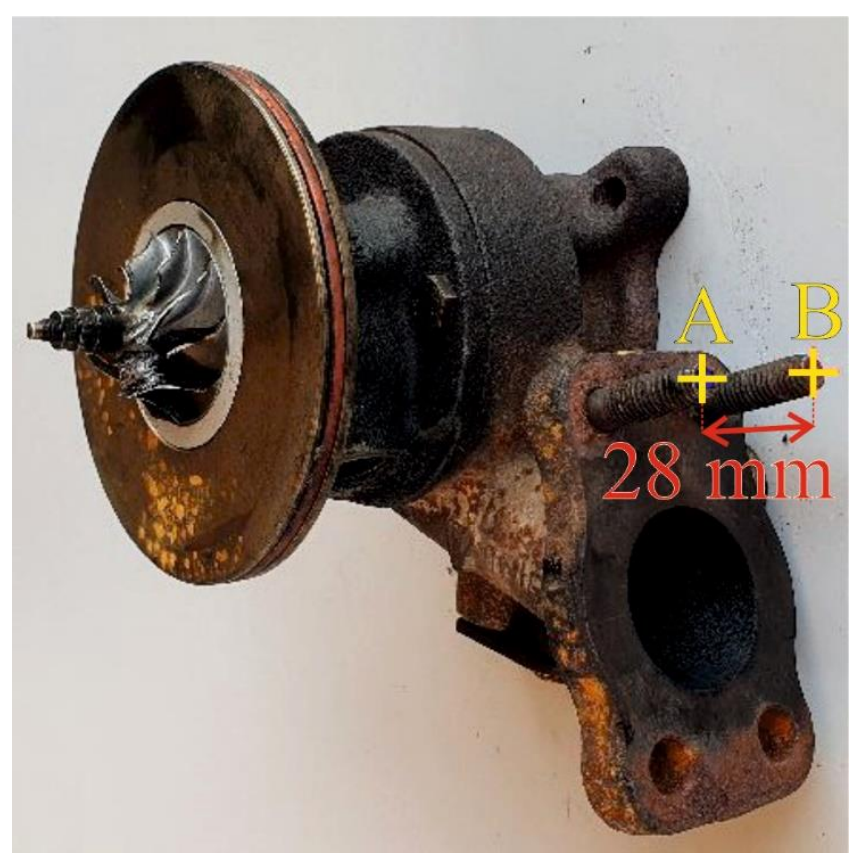

Figure 6. User tie points and scale constrains of the main component 


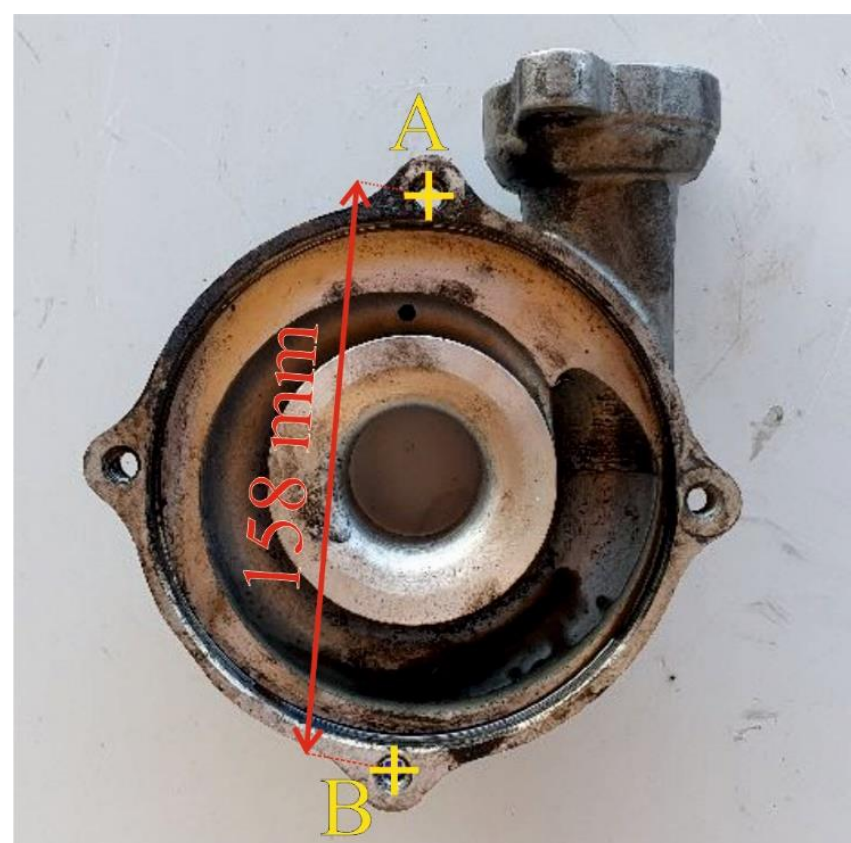

Figure 7. User tie points and scale constrains of the turbo-housing (inside)

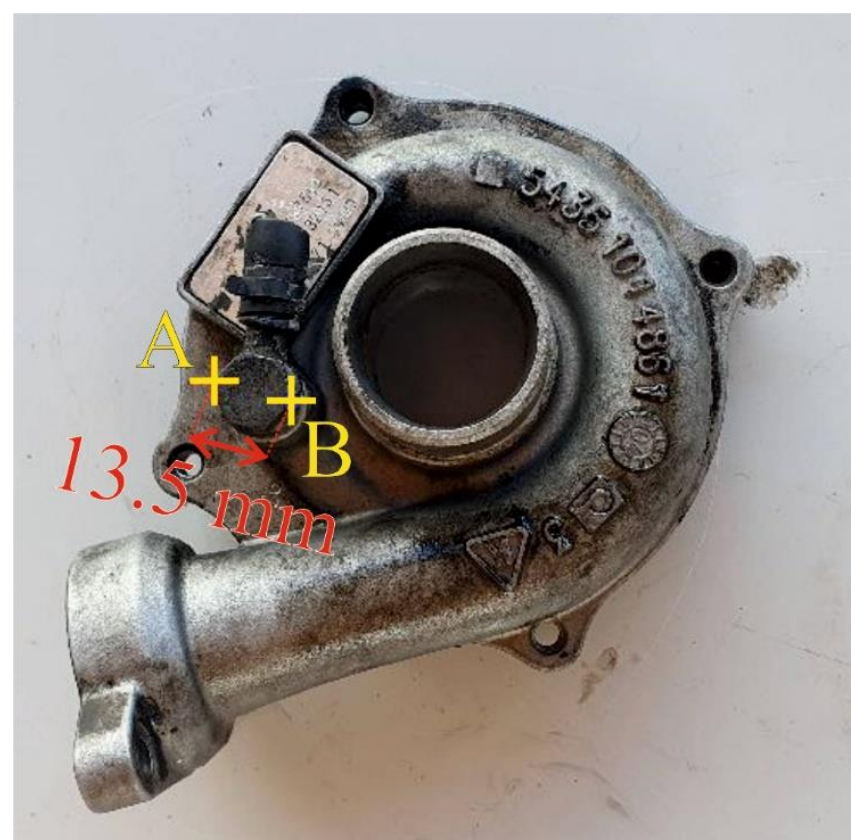

Figure 8. User tie points and scale constrains of the turbo-housing (outside)

After the aerotriangulation process, 3D point cloud data generation step was initiated. Colored point cloud was constructed by selecting the options of 1 pixels point sampling, no-compression, and visible colors for color source. The obtained 3D point cloud data was exported to Agisoft Metashape Professional in order to delete redundant points in the data-set and construct an accurate 3D solid model of the turbocharger components.

During the mesh building process, source data was selected as dense cloud which was imported from ContextCapture. Surface type was selected as arbitrary (3D) and high quality face count was applied. Interpolation was enabled and calculate vertex colors option was marked. 9,332,172 points for top turbohousing, 15,435,364 points for turbo inlet wings,
49,496,656 points for main turbo part, 32,181,638 points for turbine wheel were processed to obtain the $3 \mathrm{D}$ solid models.

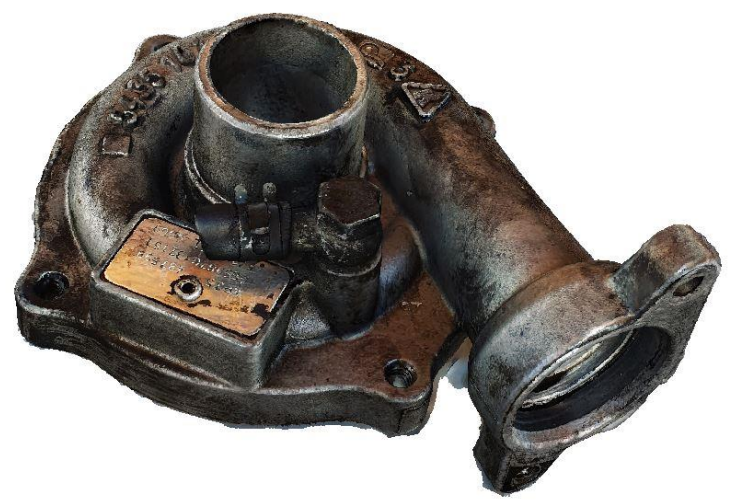

Figure 9. Turbo-housing dense point cloud obtained by ContextCapture

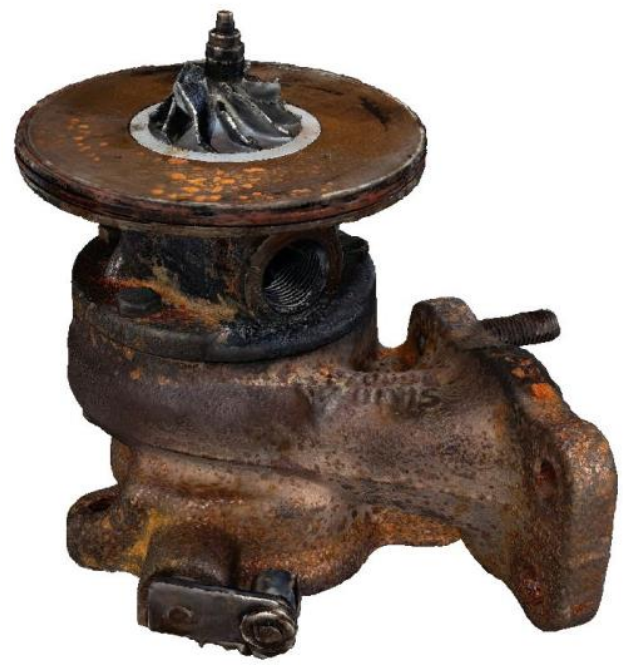

Figure 10. Main component - dense point cloud obtained by ContextCapture

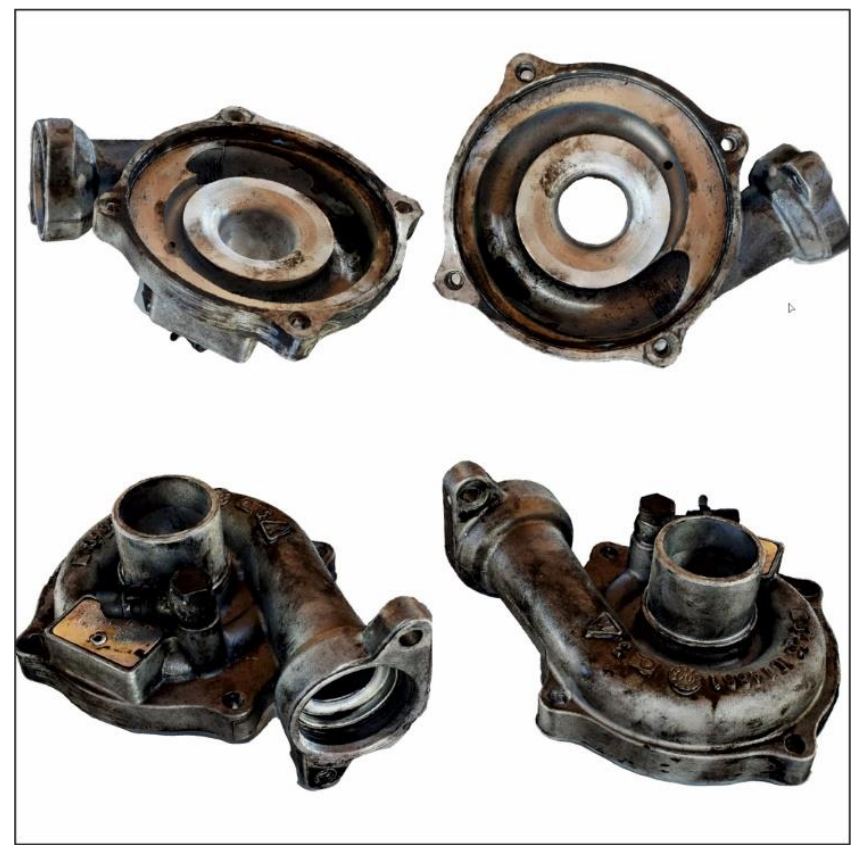

Figure 11. 3D solid model of turbo-housing obtained by Agisoft Metashape 


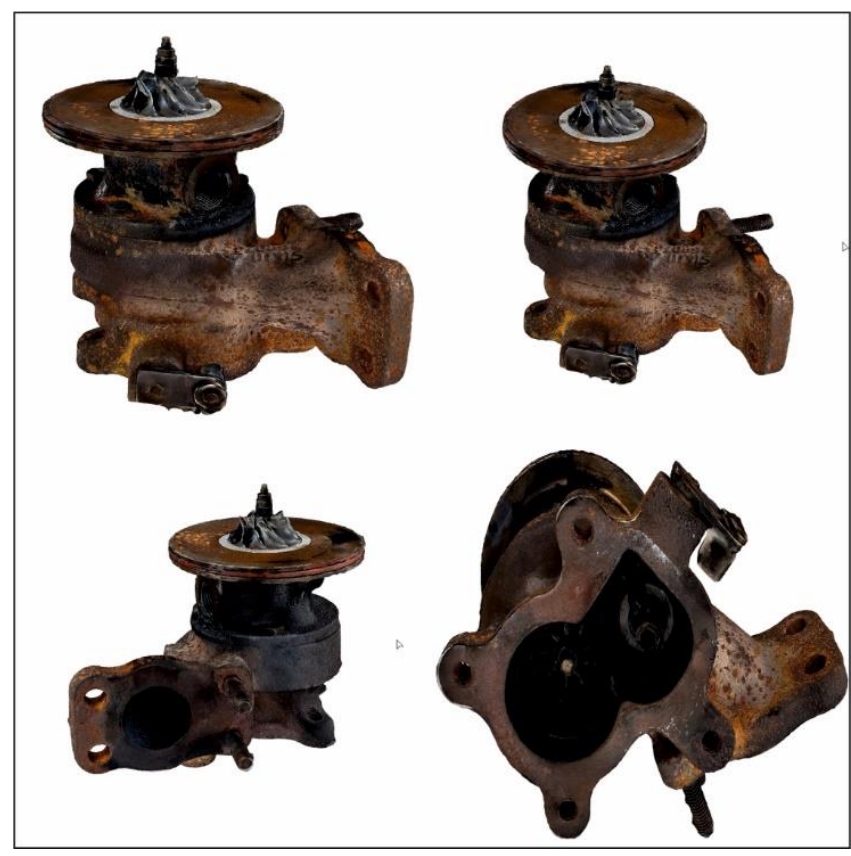

Figure 12. 3D solid model of main component obtained by Agisoft Metashape

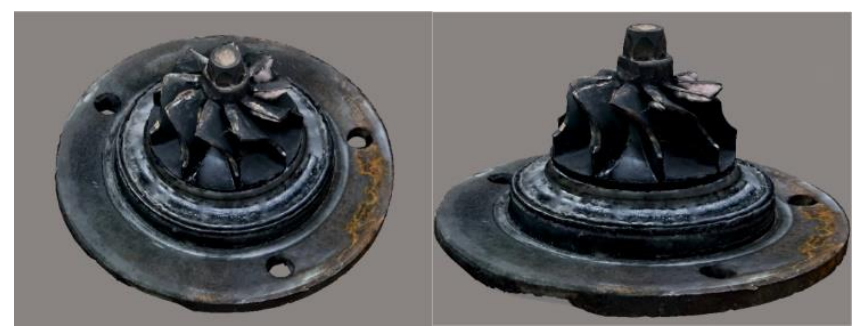

Figure 13. 3D solid model of exhaust outlet wheel obtained by Agisoft Metashape

After the 3D solid model of the turbocharger constructed, accuracy assessment was also implemented. Firstly, a stereolithographic (STL) format of the 3D model was generated to utilize it in ANSYS analysis after accuracy assessment step. With the aim of defining the metric performance of the 3D model, 5 distances between selected detail points on each turbocharger components were compared with the distances acquired from Agisoft Metashape dimensions on each 3D model.

After mesh building and accuracy assessment phases, the mesh files were exported into Rhinoceros 6 software. In Mesh2Surface module, the exact surface models of the obtained meshes were created. Then, surface continuity analyzes of each model were processed to know whether if there was any surface discontinuity or not. The next step contains Fluent analysis of a section of the compressor of the turbocharger in ANSYS 2019 software. The turbo-wing model, compressor-side, were extracted from the main 3D model and were exported into ANSYS Fluent software.

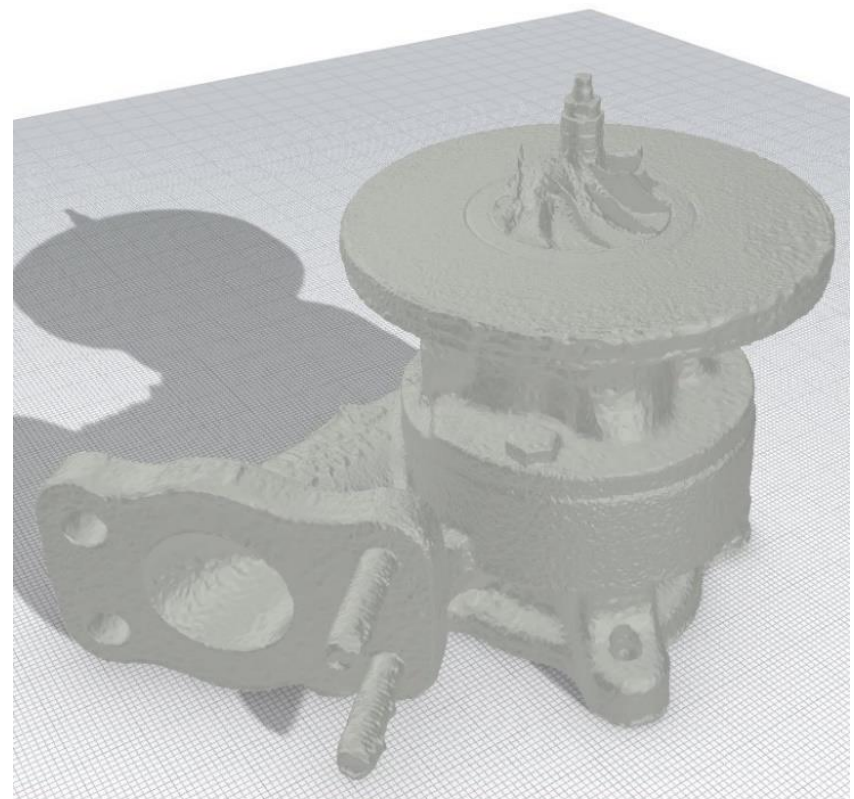

Figure 14. Stereolithographic (STL) format of the 3D model

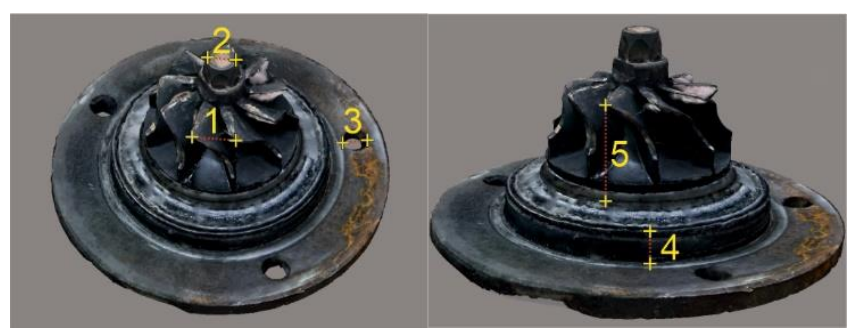

Figure 15. Detail measurements for accuracy assessment (Exhaust-side, turbine)

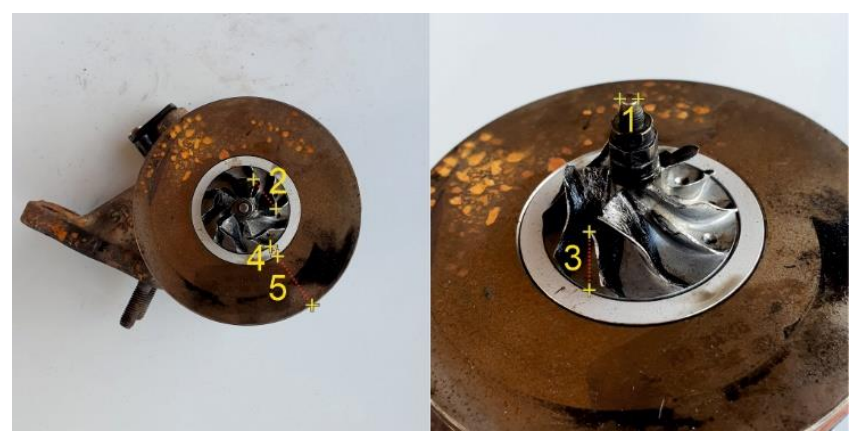

Figure 16. Detail measurements for accuracy assessment (Air-side, compressor)

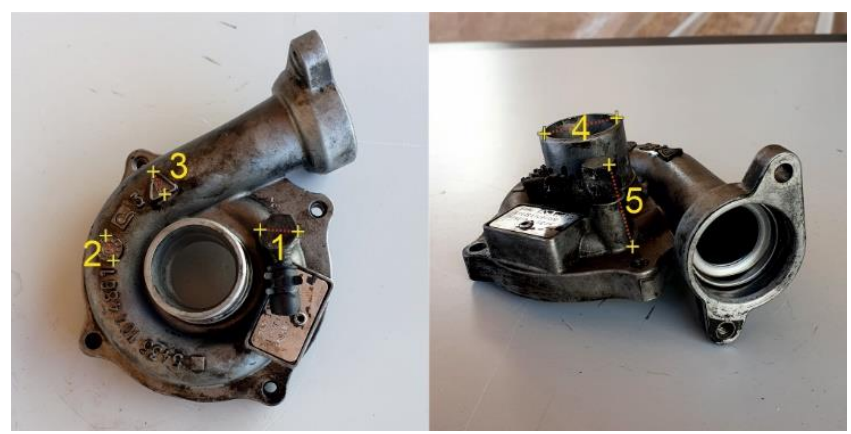

Figure 17. Detail measurements for accuracy assessment (Compressor housing) 


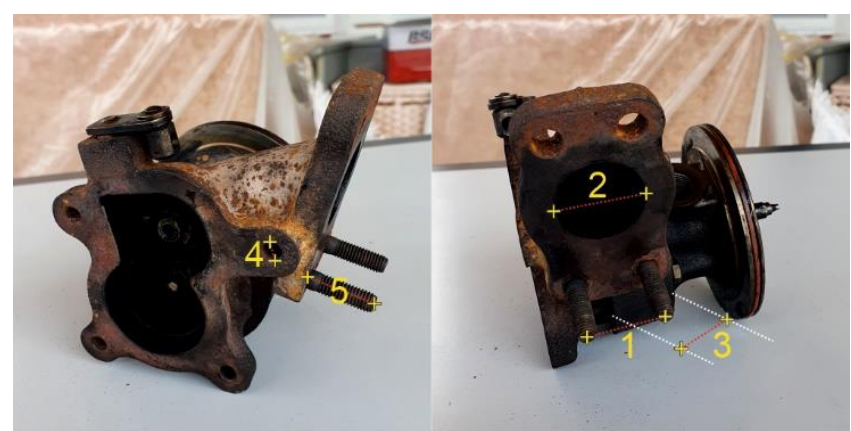

Figure 18. Detail measurements for accuracy assessment (Turbine housing)

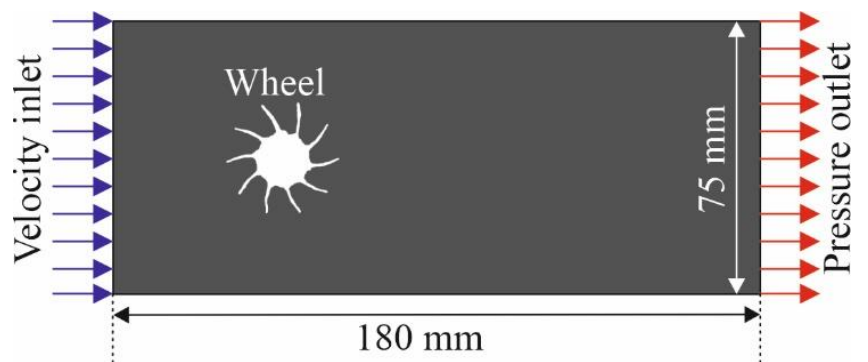

Figure 19. Domain created for Fluent analysis

Subsequently, a random horizontal section was taken from the compressor wheel. Then, it was imported into Fluent software and the domain was created as shown in "Fig. 19" above. After the geometry of the flow area has been created, meshing module was started to generate a mesh. Refinement and inflation were applied around the wheel. In addition, the mesh around the wheel has been densified. According to Bouaifi (2018), "Close to the wall, there is a thin sublayer with predominantly molecular diffusion. The sublayer has a substantial influence upon the remaining part of the flow. An adequate numerical resolution of a solution in the sublayer requires a very fine mesh because of sublayer thinness and high gradients of the solution." Linear element order and $0,005 \mathrm{~m}$ element size were applied. Growth rate of 1.2 and defeature size of $2.5 \mathrm{e}-005 \mathrm{~m}$ were decided to generate the mesh. Around the wheel, transition ratio of 0.272 and 2 maximum layers were selected in order to acquire smooth transition.

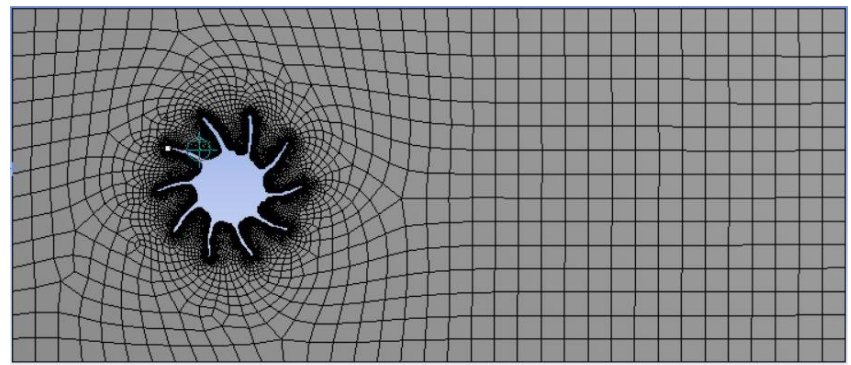

Figure 20. Domain created for Fluent analysis

After mesh generation, flow model options have been set. In calculations, double precision and serial processing were applied. Pressure-based solver, absolute velocity formulation, steady time and planar 2D space were chosen in general settings. K-epsilon ( 2 eqn.) viscous model was selected. Air was selected as flow material which has an inlet velocity of $5 \mathrm{~m} / \mathrm{s}$. Coupled scheme was selected as solution method. Least squares cell based option was selected as gradient. For pressure and momentum, second order terms options were selected. For turbulent kinetic energy and turbulent dissipation rate, first order upwind options were selected. All other settings of the software were left default.

\section{RESULTS AND DISCUSSION}

Considering the significance of design verification in the overall reverse engineering phase, few, if any, publications on part-to-CAD reverse engineering discuss modeling accuracy (Ingle 1994). After 3D models of the turbocharger were obtained, the accuracy assessment was also completed. The results of the accuracy analyzes were shown in the "Table 1-2-3-4".

Table 1. Exhaust-side turbine model [in $\mathrm{mm}$ ]

\begin{tabular}{ccccc}
\hline Length & Real & Model & V & VV \\
\hline 1 & 9.5 & 9.08 & 0.42 & 0.176 \\
2 & 6 & 5.92 & 0.08 & 0.006 \\
3 & 6.5 & 6.21 & 0.29 & 0.084 \\
4 & 5.5 & 5.13 & 0.37 & 0.137 \\
5 & 12 & 11.65 & 0.35 & 0.123 \\
& & & RMSE & $\mathbf{0 . 3 2 4}$ \\
\hline
\end{tabular}

Table 2. Suction-side compressor model [in mm]

\begin{tabular}{ccccc}
\hline Length & Real & Model & V & VV \\
\hline 1 & 3 & 2.99 & 0.01 & 0.000 \\
2 & 15 & 14.82 & 0.18 & 0.032 \\
3 & 7.5 & 8.03 & 0.53 & 0.281 \\
4 & 4 & 4.24 & 0.24 & 0.058 \\
5 & 25 & 24.72 & 0.28 & 0.078 \\
& & & RMSE & $\mathbf{0 . 3 0 0}$ \\
\hline
\end{tabular}

Table 3. Compressor housing model [in mm]

\begin{tabular}{ccccc}
\hline Length & Real & Model & V & VV \\
\hline 1 & 13.5 & 13.33 & 0.17 & 0.029 \\
2 & 9.7 & 10.03 & 0.33 & 0.109 \\
3 & 10 & 10.09 & 0.09 & 0.008 \\
4 & 31 & 30.99 & 0.01 & 0.000 \\
5 & 34.5 & 35.15 & 0.65 & 0.422 \\
& & & RMSE & $\mathbf{0 . 3 3 7}$ \\
\hline
\end{tabular}

Table 4. Turbine housing model [in $\mathrm{mm}]$

\begin{tabular}{ccccc}
\hline Length & Real & Model & V & VV \\
\hline 1 & 28 & 27.2 & 0.8 & 0.640 \\
2 & 32.5 & 32.23 & 0.27 & 0.073 \\
3 & 22 & 22.81 & 0.81 & 0.656 \\
4 & 8 & 7.75 & 0.25 & 0.063 \\
5 & 25 & 25.6 & 0.6 & 0.360 \\
& & & RMSE & $\mathbf{0 . 5 9 9}$ \\
\hline
\end{tabular}

According to "Table 1-2-3-4", the 3D model of the turbine wheel has a root mean square error (RMSE) of $0.324 \mathrm{~mm}$. The compressor's 3D model has RMSE of $0.300 \mathrm{~mm}$. As for the compressor and turbine housings' 3D models, they have RMSEs of $0.337 \mathrm{~mm}$ and $0.599 \mathrm{~mm}$ respectively. 


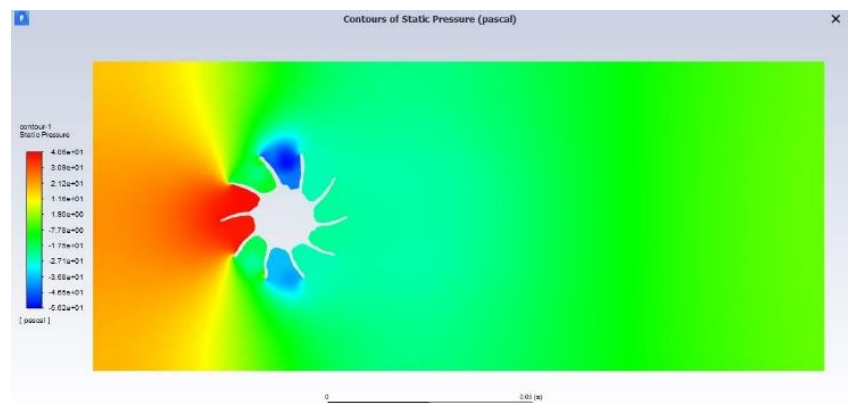

Figure 21. Contours of static pressure (in pascal)

"Fig. 21" indicates the static pressure distribution of the flow domain. Static pressure takes higher values on the inlet side of the wheel. This situation stems from that the wheel decelerates the flow as a barrier. Pressure and velocity are inversely proportional to each other. If pressure increases, the velocity decreases to keep the algebraic sum of potential energy, kinetic energy, and pressure constant. The opposite circumstance is valid for the blue (lower) values on the domain. Where the blue areas started, flow separations occurred and the flow accelerated towards the wheel.

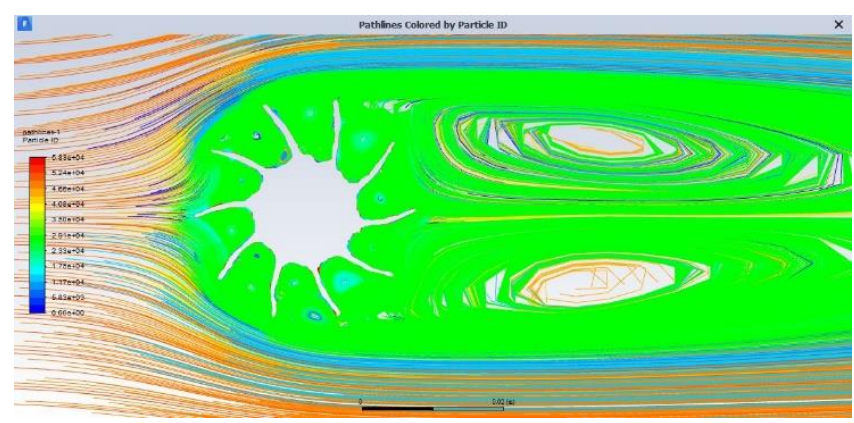

Figure 22. Colored pathlines around the wheel

"Fig. 22" shows the colored pathlines around the wheel. The flow pattern in which fluid particles move irregularly due to flow velocity or surface shape is called turbulent flow (eddy flow). As seen above, many flow irregularities are observed around the wheel. This circumstance was derived from the sharp ends of the wheel. Sharp ends disrupt the continuity of the flow. Streamlines intersect each other, particles mingle with each other, creating a turbulent flow.

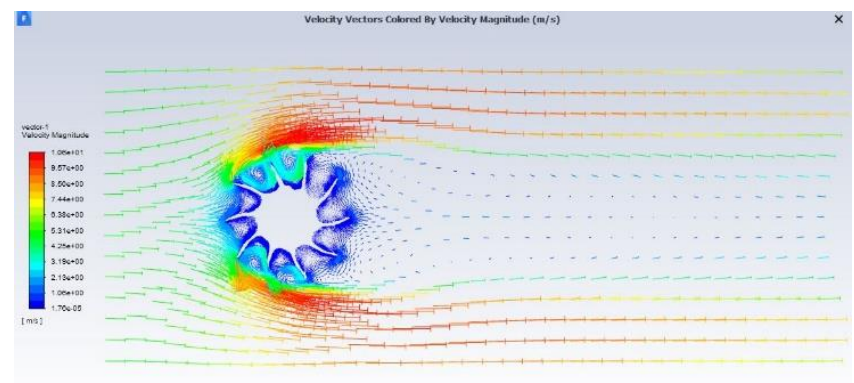

Figure 23. Velocity vectors of the flow domain

"Fig. 23" indicates the velocity vectors of the domain. Higher velocity magnitudes (in m/s) are represented by the color red, while lower values are represented by the color blue. Vector distribution around the wheel shows that the velocity magnitudes take lower values between the wings. Subsequent to the sharp ends of the wheel, speed values increase due to sudden pressure drop. Velocity vectors change direction also.

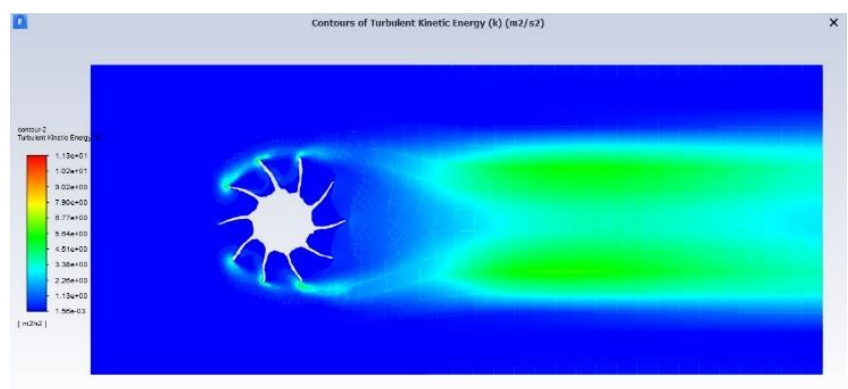

Figure 24. Contours of turbulent kinetic energy (k)

"Fig. 24" demonstrates the contours of turbulent kinetic energy $(\mathrm{k})$ in $\mathrm{m}^{2} / \mathrm{s}^{2}$. Simply, turbulence is not observed from the inlet area to the wheel. With distortion of streamlines at sharp ends, turbulences occurred and turbulent kinetic energy $(\mathrm{k})$ increased.

Table 5. Moments on the wheel [in N.m]

\begin{tabular}{cccc}
\hline Zone & Pressure & Viscous & Total \\
\hline Wheel & -0.1612 & 0.0015 & $\mathbf{- 0 . 1 5 9 7}$ \\
\hline
\end{tabular}

The moment values that the cross section is exposed to is shown in the "Table 5". From the values above, viscous/pressure moments ratio is calculated as $0.93 \%$.

\section{CONCLUSION}

There are many reasons to use reverse engineering. One of the essential purpose of selecting RE as an engineering calculation method is the deficiency of $3 \mathrm{D}$ CAD models of the existing parts. As a result of conducting this research, it is clear to be seen that accurate 3D CAD models of existing machine parts and their engineering calculations can be created/made by using mobile photogrammetric surveys and common engineering softwares. In this research, a damaged turbocharger of a car was separated into its parts and 3D CAD models of each part were acquired. Then, a basic flow calculation around the compressor wheel of the turbocharger was carried out by extracting a $2 \mathrm{D}$ section of the compressor.

The findings that are presented in this study suggest that mobile photogrammetric methods provide fast, detailed and accurate 3D documentation of mechanical parts. Accuracy analyzes of the 3D models showed that less than $0.5 \mathrm{~mm}$ accuracy can be obtained without difficulty.

This study also indicates that many engineering calculations can be made using $3 \mathrm{D}$ models of the mechanical parts.

All things considered, mobile photogrammetric survey is an effective, easy-to-use and accurate method for reverse engineering calculations.

In future studies, handheld laser scanners can be utilized to obtain 3D models of mechanical parts, and can be compared to the mobile photogrammetric results to become aware of which method is more suitable in 3D modeling of mechanical parts. 


\section{ACKNOWLEDGEMENT}

The author gratefully appreciates the sincere thanks to the Geomatics Engineering Department of Mersin University for their support and contributions to the development of this work.

\section{Conflicts of interest:}

The authors declare no conflicts of interest.

\section{REFERENCES}

Anwer N \& Mathieu L (2016). From reverse engineering to shape engineering in mechanical design. CIRP Annals - Manufacturing Technology, 65(1), 165-168. https://doi.org/10.1016/j.cirp.2016.04.052

Bouaifi M (2018, February 6). Re: Why do we need Finer Mesh near the Wall? Mathematical Reason? [Discussion post]. Researchgate. https://www.researchgate.net/post/Why-do-weneed-Finer-Mesh-near-the-Wall-MathematicalReason

Buonamici F, Carfagni M, Furferi R, Governi L, Lapini A \& Volpe Y (2018). Reverse engineering of mechanical parts: A template-based approach. Journal of Computational Design and Engineering, 5(2), 145159. https://doi.org/10.1016/j.jcde.2017.11.009

Deja M, Dobrzyński M \& Rymkiewicz M (2019). Application of Reverse Engineering Technology in Part Design for Shipbuilding Industry. Polish Maritime Research, 26(2), 126-133. https://doi.org/10.2478/pomr-2019-0032

Doğan Y \& Yakar M (2018). Gis and Three-Dimensional Modeling for Cultural Heritages. International Journal of Engineering and Geosciences, 50-55. https://doi.org/10.26833/ijeg.378257

Dúbravčík M \& Kender Š (2012). Application of reverse engineering techniques in mechanics system services. Procedia Engineering, 48, 96-104. https://doi.org/10.1016/j.proeng.2012.09.491
K A Ingle, Reverse Engineering. New York: McGraw-Hill, 1994.

Kumar A, Jain P K \& Pathak P M (2013). Reverse engineering in product manufacturing: an overview. Daaam International Scientific Book, 2013. p. 665678.

Thompson W B, Owen J C, De St. Germain H J, Stark S R \& Henderson T C (1999). Feature-based reverse engineering of mechanical parts. IEEE Transactions on Robotics and Automation, 15(1), 57-66. https://doi.org/10.1109/70.744602

Ulvi A, Yakar M, Yiğit A \& Kaya Y (2019). The Use of Photogrammetric Techniques in Documenting Cultural Heritage: The Example of Aksaray Selime Sultan Tomb. Universal Journal of Engineering Science, 7(3), 64-73.

Unal M, Yakar M, Yildiz F (2004). Discontinuity surface roughness measurement techniques and the evaluation of digital photogrammetric method. In: Proceedings of the 20th international congress for photogrammetry and remote sensing, ISPRS, 11031108

Verim Ö \& Yumurtacı M (2020). Application of reverse engineering approach on a damaged mechanical part. International Advanced Researches and Engineering Journal, 4(1), 21-28. https://doi.org/10.35860/iarej.687014

Yakar M \& Yılmaz H M (2008). Kültürel Miraslardan Tarihi Horozluhan'ın Fotogrametrik Rölöve Çalışması ve 3 Boyutlu Modellenmesi. Selçuk Üniversitesi Mühendislik, Bilim ve Teknoloji Dergisi, 23(2), 25-33.

Yilmaz H M, Karabork H, Yakar M (2000). Yersel Fotogrametrinin Kullanım Alanları, Nigde Universitesi Muhendislik Bilimleri Dergisi, 4(1), 1828.

Yilmaz H M, Yakar M \& Yildiz F (2008). Digital photogrammetry in obtaining of 3D model data of irregular small objects. The International Archives of the Photogrammetry, Remote Sensing and Spatial Information Sciences, 37, 125-130. 